\title{
A hybrid particle swarm optimization (PSO) with chi-square and stable mutation jump strategy
}

\author{
Raazia Anum ${ }^{1, *}$, Muhammad Imran ${ }^{2}$, Rathiah Hahsim ${ }^{3}$, Azhar Mahmood ${ }^{2}$, Saqib Majeed ${ }^{1}$ \\ 1University Institute of Information Technology, PMAS Arid Agriculture University, Rawalpindi, Paksitan \\ ${ }^{2}$ Shaheed Zulfikar Ali Bhutto Institute of Science and Technology (SZABIST), Islamabad, Paksitan \\ 3Universiti Tun Hussein Onn Malaysia, Johor, Malaysia
}

\section{A R T I C LE IN F O}

\section{Article history:}

Received 25 August 2016

Received in revised form

17 November 2016

Accepted 28 November 2016

Keywords:

Chi-square distribution

Cost value

Global best particle

Global minima

Test functions

Stable distribution

\begin{abstract}
A B S T R A C T
Particle Swarm is a heuristic technique based on collective behavior of birds. Several researches depicts that the PSO suffers from untimely convergence. To defeat the issue of untimely convergence in PSO several solutions are proposed to increase the performance in term of accuracy. This paper suggests a new hybrid mutation operator which used Chi-square and stable distribution. The hybrid mutation operator leads the swarm from local minima to global minima for better solution. To validate the new hybrid scheme, a 12 benchmark optimization functions are used in experiment and compared the result with pervious 6 variants of PSO, proposed variant achieved better results than previous 6 variants.
\end{abstract}

(C) 2016 The Authors. Published by IASE. This is an open access article under the CC BY-NC-ND license (http://creativecommons.org/licenses/by-nc-nd/4.0/).

change their positions according to following equation (Eqs. 1 and 2):

Swarm Intelligence (SI) is a branch of Artificial intelligence. The idea about Swarm intelligence was first presented by Beni and Wang (1989) cued by the mutual behavior of swarm-interaction. Various algorithm of Swarm Intelligence such as Particle Swarm Optimization, Fish Schooling Search, Artificial Immune System, Ant Colony Optimization, Bee Colony Optimization, Cat Swarm Optimization and Bat Algorithm etc. achieved good performance in different application areas. Most famous algorithm of SI is Particle Swarm Optimization and Ant Colony Optimization.

Kennedy and Eberhart (1995) presented the idea of Particle Swarm Optimization. This algorithm is observed to solve the optimization related problems. PSO is a population based meta-heuristic technique which is stimulated by the social phenomena of birds. The flow chart of PSO is presented in Fig. 1. In particle swarm optimization, homogenous particles called agents or birds flying in the region for the optimal solution. These birds store their best positions locally and interact with each other to find the global best position in the search space and

\footnotetext{
* Corresponding Author.

Email Address: raaxiaanumm@gmail.com (R. Anum)

https://doi.org/10.21833/ijaas.2016.12.007

2313-626X/@ 2016 The Authors. Published by IASE.

This is an open access article under the CC BY-NC-ND license

(http://creativecommons.org/licenses/by-nc-nd/4.0/)
}

velocity $_{\mathrm{i}}^{\mathrm{t}+1}=\mathrm{v}_{\mathrm{i}}^{\mathrm{t}}+\mathrm{c} 1 * \mathrm{r} 1 *\left(\right.$ localbest $_{\mathrm{i}}^{\mathrm{t}}-$ position $\left._{\mathrm{i}}^{\mathrm{t}}\right)+\mathrm{c} 2 * \mathrm{r} 2 *$

(globalbest $^{\mathrm{t}}-$ position $_{\mathrm{i}}^{\mathrm{t}}$ )

Position $_{\mathrm{i}}^{\mathrm{t}+1}=$ velocity $^{\mathrm{t}+1}+$ position $^{\mathrm{t}}$

Sometimes these particles realize that they found optimal solution in the search space. But actually they are suffering from untimely convergence and they stuck into local minima. However, the optimal solution is present somewhere else in the search space. To tackle the problem of untimely convergence researchers are being trying to develop various solutions to enhance the functioning of PSO in term of accuracy. This paper also presents a new solution to avoid the untimely convergence of PSO.

The proposed paper is organized as, in Part 2, a brief review of related work is defined. Section 3, deals with proposed methodology scheme. The parameter settings, experimental results, and discussions on hybrid mutation jump strategy are set in Section 4. Lastly, Section 5 offers conclusion of new mutation scheme.

\section{Literature review}

In previous epoch, a diversity of variation has been produced to increase the performance of PSO in terms of accuracy, global best, premature convergence etc. Many strategies such as introducing the concept of mutation operator, inertia weight and initialization were developed to tackle the problems 
of PSO. However, in this research article only mutation based variants of PSO will be discussed in following section.

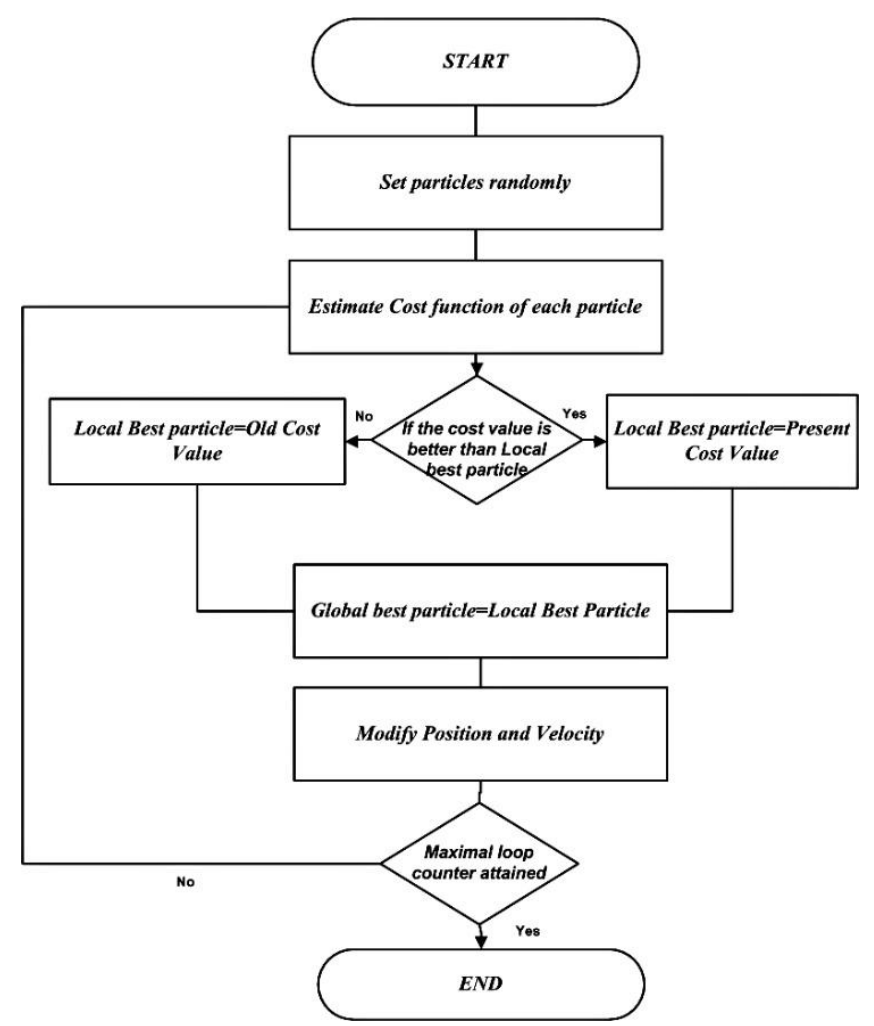

Fig. 1: Flowchart of basic PSO Algorithm

Higashi and Iba (2003) introduced a mutation operator based on Gaussian distribution to improve the performance of PSO. In the study, small ranges of benchmark functions were used and verified the results with and without mutation technique. Esquivel and Coello (2003) presented a mutation operator on multimodal benchmark function (Esquivel and Coello, 2003).

Andrews (2006) examined the mutation operators for particle swarm optimization with fewer benchmark functions. Wang and Yong (2007) introduce a Cauchy mutation operator. The basic goal is to introduce the Cauchy operator to escape the PSO from local minima and to move towards the global minima. To validate the proposed technique unimodal and multimodal benchmark functions were used.

Li et al. (2007) introduced mutation operator and crossover technique on global best particles to leads the swarm toward optimal solution. This technique implemented on 8 functions with less than 30 dimensions.

Krohling and Eduardo (2009) introduced hybrid jump on the bare bone PSO. The hybrid jump strategy uses Gaussian and Cauchy operator. To assure the performance of bare bone PSO with jump strategy, comparison of jump strategy is done with bare bone PSO. Through experiments it was proved the performance of bare bone PSO with hybrid jump is better than basic bare bone PSO.

Zhan et al. (2009) introduced the adaptive mutation operator based on adaptive distribution. This operator jumped out the particles from local minima to global minima with the help of adaptive operator. To test the functioning of proposed technique, unimodal and multi modal functions were used.

$\mathrm{Wu}$ and Min, (2009) demonstrated power mutation scheme on global best particles in 2009.The aim to employ the power operator on global best particle to prevent the premature convergence. Results indicated that the power mutation PSO has better performance than other variants of PSO.

Imran et al. (2011) presented a student $\mathrm{T}$ mutation based PSO which saves the particles from premature convergence and jumps out the particles from local minima to global minima for better solution.

Imran et al. (2012) introduced the overview of different variants of PSO regarding performance of the algorithm. In 2013 Hashim et al. (2013) demonstrated the concept of student $\mathrm{T}$ mutation operator with opposition based PSO to prevent from premature convergence. Several benchmark functions were utilized to assure the performance of Opposition-based PSO with student t mutation.

Hashim et al. (2013) presented a new operator using triangular distribution (Hashim et al., 2013). The aim to this distribution is to prevent particles form premature convergence. To validate the performance of new triangular mutation operator various benchmark function were used.

Imran et al. (2014) introduced the Laplace mutation operator via Laplace distribution. It was also applied on global best particle which prevent 
global best and other particles from untimely convergence. To validate this technique author applied the technique on 18 benchmark function. Through experimental study it was proved that the proposed technique is better than the previous versions of PSO.

Though many alternatives have been developed to improve the performance of PSO in term of accuracy which prevents the particles from untimely convergence. However, there is still need to improve the performance of PSO and make PSO algorithm more efficient and energetic.

\section{Proposed methodology scheme}

In simple PSO, birds fly in the region and keep up its global best and local best particles positions. Occasionally particles trapped in the local minima due to untimely convergence and need of optimal solution which is present in global minima. So for this purpose there is need to lead swarm in to global optima for optimal solution. The new solution is to increase the performance of PSO in term of accuracy is the combination of two distribution named chisquare and stable distribution which is named as HPSO. Using these two distributions, a random number is generated using Eq. 3 which employs on global best particle which mutate the particles from local minimum to global minimum. The flow chart of proposed methodology is presented in Fig. 2 (Eqs. 4 and 5).

$R=\operatorname{stblrnd}(\alpha, \beta, \gamma, \delta)+\operatorname{chi} 2 r n d(v))$

where,

$\alpha$ : Stability Parameter

$\beta$ : Skewness Parameter

$\gamma$ : Scale Parameter

$\delta$ : Location Paramter

v: Degree of Freedom

The hybrid distribution as follows:

mutatedglobalbest ${ }_{j}=$

$$
\left\{\begin{array}{c}
\text { globalbest }_{j}-R\left(\text { globalbest }_{j}-x^{\text {lower }}\right) \text { if } t<r \\
\text { globalbest }_{j}+R\left(x^{\text {upper }}-\text { globalbest }_{j}\right) \text { if } t \geq r
\end{array}\right.
$$

while,

$x^{\text {lower }}=$ Minimum $\left(\right.$ globalbest $\left._{j}\right)$ and $x^{\text {upper }}=$ Maximum

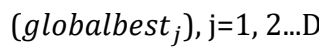

where,

$$
\begin{aligned}
& \left(x^{\text {lower }}, x^{\text {upper }}\right): \text { the Lower and Upper boundary } \\
& \text { of region: } \\
& r: \text { random number } \\
& t: t=\left(x-x^{\text {lower }}\right) /\left(x^{\text {upper }}-x^{\text {lower }}\right) .
\end{aligned}
$$

The proposed Methodology algorithm is as follows:

\section{Algorithm 1}

Hybrid PSO Algorithm

1. Set out

2. $\quad$ op size=population size

3. dim $=$ dimension size

4. Iter= set maximum iteration
5. PSO runs $=$ set $P S O$ runs

6. $c 1=c 2=1.4983$

7. while iteration $<=$ maximum iteration

8. for entirely swarm $i$

9. Modify swarm i position through Eq. 1

10. Modify swarm i velocity through Eq. 2

11. $E N D$

12. Modify the local particlesand global best particle in the swarm.

13. Evaluate the new search boundary using Eq. 5

14. Applying the hybrid mutation technique on global best by using Eq. 4

15. if the fresh global best is more beneficial than old global best

16. switch the global best with fresh one

17. end if

18. iteration $=$ iteration +1

19. end while

20. close

\section{Experimental results}

To formalize the performance of suggested scheme, 12 benchmark functions were used in experiment given in Table 1. These functions are Sphere, Griewank, schwefel function 2, Conville, Ackley, Schaffer 2, Easom, Hump camel 6, Zarkharov, Drop wave, Alpine and Schwefel 2.22 Function. Identical parameter settings were applied on the overall process for true comparisons which are swarm size and number of PSO runs is 30 . The three dimension sizes are 10, 20 and 30 along 1000, 1500 and 2000 iterations. Linear decreasing inertia weight was used between ranges 0.4 to 0.9 and the $\mathrm{c} 1$ and c2 is 1.4983 .

\subsection{Analysis}

The result analysis is performed on six different variants of PSO w.r.t mutation technique in Table 2. These variants are basic PSO, Adaptive Mutated PSO, Cauchy Mutated PSO, Laplace Mutated PSO, Power Mutated PSO and Student T PSO.

The new hybrid mutated proposed technique achieved best result on $f_{1}$ and $f_{4}$, where iterations is 1000 with 10 dimensions. However, by increasing the iterations and dimensions the performance of the proposed technique decreased.

$f_{2}, f_{3}$ and $f_{5}$ give good results on the proposed technique. $f_{6}$ gives maximum accuracy with hybrid mutation technique. Overall same performance on $f_{7}$ and $f_{8}$ with all other variants of PSO. The performance of $f_{9}, f_{10}, f_{11}$ and $f_{12}$ are best on Hybrid mutation scheme.

\section{Conclusion}

The paper suggests another variant of PSO to improve the performance of PSO in terms of accuracy. It is concluded from the results that our new scheme performs better than other variants of PSO and helps to get better the performance in terms of accuracy. The suggested scheme works on global best particle which suffers from untimely 
convergence and minimizing the fitness value. The hybrid mutation scheme employs on global best particles which jump out the particles from local minimum to global minimum.

\section{Acknowledgements}

The author would like to thank Universiti Tun Hussein Onn Malaysia for supporting this research work under grant the MDR Grant Vote 1315. The Author would also like to thanks Shaheed Zulifqar Ali Bhuto Institute of Science and Information Technology, Islamabad along with University Institute of Information Technology, Rawalpindi, Pakistan for providing the platform to conduct this research work.

Table 1: Results of PSO Variants

\begin{tabular}{|c|c|c|c|c|c|c|c|c|c|}
\hline & DIM & ITERATION & PSO & PMPSO & AMPSO & STPSO & CPSO & LMPSO & HPSO \\
\hline \multirow[t]{3}{*}{ f1 } & 10 & 1000 & $5.03 \mathrm{E}-53$ & $2.53 \mathrm{E}-96$ & 4. $18 \mathrm{E}-53$ & 8.98E-98 & I.73E-64 & $2.84 \mathrm{E}-97$ & $1.5882 \mathrm{e}-120$ \\
\hline & 20 & 1500 & $4.45 \mathrm{E}-17$ & $4.66 \mathrm{E}-81$ & 7.37E-17 & $2.96 \mathrm{E}-90$ & $3.13 \mathrm{E}-27$ & $5.72 \mathrm{E}-87$ & $7.8756 \mathrm{e}-48$ \\
\hline & 30 & 2000 & I.79E-07 & $2.86 \mathrm{E}-65$ & I.66E-10 & $7.09 \mathrm{E}-76$ & $2.39 \mathrm{E}-14$ & $9.19 \mathrm{E}-78$ & $1.7591 \mathrm{e}-28$ \\
\hline \multirow[t]{3}{*}{ f2 } & 10 & 1000 & $1.00 \mathrm{E}+00$ & $1.00 \mathrm{E}+00$ & $1.00 \mathrm{E}+00$ & $1.00 \mathrm{E}+00$ & $1.00 \mathrm{E}+00$ & $1.00 \mathrm{E}+00$ & $0.00 \mathrm{E}+00$ \\
\hline & 20 & 1500 & $1.00 \mathrm{E}+00$ & $1.00 \mathrm{E}+00$ & $1.00 \mathrm{E}+00$ & $1.00 \mathrm{E}+00$ & $1.00 \mathrm{E}+00$ & $1.00 \mathrm{E}+00$ & $1.1102 \mathrm{e}-16$ \\
\hline & 30 & 2000 & $1.00 \mathrm{E}+00$ & $1.00 \mathrm{E}+00$ & $1.00 \mathrm{E}+00$ & $1.00 \mathrm{E}+00$ & $1.00 \mathrm{E}+00$ & $1.00 \mathrm{E}+00$ & $5.3291 \mathrm{e}-15$ \\
\hline \multirow[t]{3}{*}{ f3 } & 10 & 1000 & $1.04 \mathrm{E}-11$ & $1.76 \mathrm{E}-16$ & $1.32 \mathrm{E}-11$ & $6.19 \mathrm{E}-16$ & $1.72 \mathrm{E}-17$ & $2.06 \mathrm{E}-17$ & $0.00 \mathrm{E}+00$ \\
\hline & 20 & 1500 & 5.36E-01 & $9.70 \mathrm{E}-01$ & 3.59E-01 & $3.12 \mathrm{E}-02$ & $1.68 \mathrm{E}-02$ & $4.64 \mathrm{E}-06$ & $0.00 \mathrm{E}+00$ \\
\hline & 30 & 2000 & $1.03 \mathrm{E}+01$ & $1.62 \mathrm{E}+01$ & $8.96 \mathrm{E}+00$ & $6.75 \mathrm{E}-01$ & $3.61 \mathrm{E}+00$ & $4.07 \mathrm{E}-04$ & $0.00 \mathrm{E}+00$ \\
\hline \multirow[t]{3}{*}{$\mathrm{f} 4$} & 10 & 1000 & 1.33E-03 & - & $1.08 \mathrm{E}-03$ & $1.77 \mathrm{E}-06$ & $1.08 \mathrm{E}-03$ & - & $4.4945 \mathrm{e}-13$ \\
\hline & 20 & 1500 & $8.24 \mathrm{E}-05$ & - & $1.59 \mathrm{E}-04$ & $1.33 \mathrm{E}-07$ & $1.59 \mathrm{E}-04$ & - & $1.30 \mathrm{E}+00$ \\
\hline & 30 & 2000 & $1.50 \mathrm{E}-05$ & - & I.3IE-05 & $1.56 \mathrm{E}-09$ & I.3IE-05 & - & $2.3568 \mathrm{e}-08$ \\
\hline \multirow[t]{3}{*}{ f5 } & 10 & 50 & $2.01 \mathrm{E}+01$ & $2.01 \mathrm{E}+01$ & $2.01 \mathrm{E}+01$ & - & $2.01 \mathrm{E}+01$ & $2.01 \mathrm{E}+01$ & $2.289 \mathrm{e}-05$ \\
\hline & 20 & 800 & $2.01 \mathrm{E}+01$ & $2.01 \mathrm{E}+01$ & $2.01 \mathrm{E}+01$ & - & $2.01 \mathrm{E}+01$ & $1.99 \mathrm{E}+01$ & $1.7562 \mathrm{e}-06$ \\
\hline & 30 & 100 & $2.01 \mathrm{E}+01$ & $2.01 \mathrm{E}+01$ & $2.01 \mathrm{E}+01$ & - & $2.01 \mathrm{E}+01$ & $1.90 \mathrm{E}+01$ & $1.2082 \mathrm{e}-06$ \\
\hline \multirow[t]{3}{*}{ f6 } & 2 & 100 & $1.53 \mathrm{E}-07$ & $4.532 \mathrm{E}-08$ & $1.58 \mathrm{E}-08$ & - & $1.46 \mathrm{E}-07$ & $3.67 \mathrm{E}-09$ & $0.00 \mathrm{E}+00$ \\
\hline & 2 & 400 & $2.88 \mathrm{E}-12$ & $4.57 \mathrm{E}-13$ & $5.76 \mathrm{E}-13$ & - & $6.67 \mathrm{E}-11$ & $2.67 \mathrm{E}-16$ & $0.00 \mathrm{E}+00$ \\
\hline & 2 & 800 & $7.55 \mathrm{E}-15$ & $3.06 \mathrm{E}-13$ & $2.88 \mathrm{E}-16$ & - & $4.33 \mathrm{E}-14$ & 0 & $0.00 \mathrm{E}+00$ \\
\hline f7 & 2 & 100 & $-1.01 \mathrm{E}+00$ & $-1.01 \mathrm{E}+00$ & $-1.01 \mathrm{E}+00$ & - & $-1.01 \mathrm{E}+00$ & $-1.01 \mathrm{E}+00$ & $-1.01 \mathrm{E}+00$ \\
\hline f8 & 2 & 100 & $-1.04 \mathrm{E}+00$ & $-1.04 \mathrm{E}+00$ & $-1.04 \mathrm{E}+00$ & - & $-1.04 \mathrm{E}+00$ & $-1.04 \mathrm{E}+00$ & $-1.04 \mathrm{E}+00$ \\
\hline \multirow[t]{3}{*}{ f9 } & 10 & 1000 & $3.18 \mathrm{E}-17$ & $6.53 \mathrm{E}-44$ & $1.68 \mathrm{E}-17$ & - & $2.11 \mathrm{E}-22$ & $3.68 \mathrm{E}-46$ & $1.0927 \mathrm{e}-84$ \\
\hline & 20 & 1500 & $3.82 \mathrm{E}+02$ & $2.45 \mathrm{E}+00$ & $2.17 \mathrm{E}+02$ & - & $1.45 \mathrm{E}+02$ & $2.08 \mathrm{E}+0$ & $1.5811 \mathrm{e}-98$ \\
\hline & 30 & 2000 & $2.73 \mathrm{E}+03$ & $2.57 \mathrm{E}+02$ & $1.72 \mathrm{E}+03$ & - & $1.49 \mathrm{E}+03$ & $6.15 \mathrm{E}+2$ & $3.3123 \mathrm{e}-11$ \\
\hline $\mathrm{f} 10$ & 2 & 1000 & $2.95 \mathrm{E}-13$ & $8.09 \mathrm{E}-13$ & $3.04 \mathrm{E}-14$ & - & $2.16 \mathrm{E}-13$ & $3.26 \mathrm{E}-12$ & $-9.36 \mathrm{E}-01$ \\
\hline \multirow[t]{3}{*}{ f11 } & 10 & 1000 & $9.57 \mathrm{E}-08$ & $3.66 \mathrm{E}-07$ & $1.74 \mathrm{E}+03$ & - & $5.88 \mathrm{E}-08$ & $2.63 \mathrm{E}-15$ & $0.00 \mathrm{E}+00$ \\
\hline & 20 & 1500 & $2.25 \mathrm{E}-01$ & $4.5 \mathrm{E}-02$ & $3.74 \mathrm{E}-01$ & - & $8.64 \mathrm{E}-01$ & $1.27 \mathrm{E}-14$ & $5.0382 \mathrm{e}-14$ \\
\hline & 30 & 2000 & $4.91 \mathrm{E}+00$ & $1.94 \mathrm{E}+00$ & $8.17 \mathrm{E}+00$ & - & $7.67 \mathrm{E}+00$ & $2.5 \mathrm{E}-15$ & $0.00 \mathrm{E}+00$ \\
\hline \multirow[t]{3}{*}{ f12 } & 10 & 50 & $2.15 \mathrm{E}+02$ & $1.57 \mathrm{E}+02$ & $1.64 \mathrm{E}+02$ & - & $1.65 \mathrm{E}+02$ & $1.93 \mathrm{E}+02$ & $4.7838 \mathrm{e}-05$ \\
\hline & 20 & 80 & $1.16 \mathrm{E}+02$ & $6.41 \mathrm{E}+02$ & $7.99 \mathrm{E}+02$ & - & $7.54 \mathrm{E}+02$ & $7.86 \mathrm{E}+02$ & $3.3745 \mathrm{e}-06$ \\
\hline & 30 & 100 & $1.13 \mathrm{E}+03$ & $1.23 \mathrm{E}+03$ & $1.36 \mathrm{E}+03$ & - & $1.43 \mathrm{E}+03$ & $1.22 \mathrm{E}+3$ & $1.4215 \mathrm{e}-07$ \\
\hline
\end{tabular}

Table 2: Test functions

Name of Benchmark Functions

Sphere Function: $\mathrm{f}(\mathrm{x})=\sum_{\mathrm{i}=1}^{\mathrm{d}} \mathrm{x}_{\mathrm{i}}^{2}$

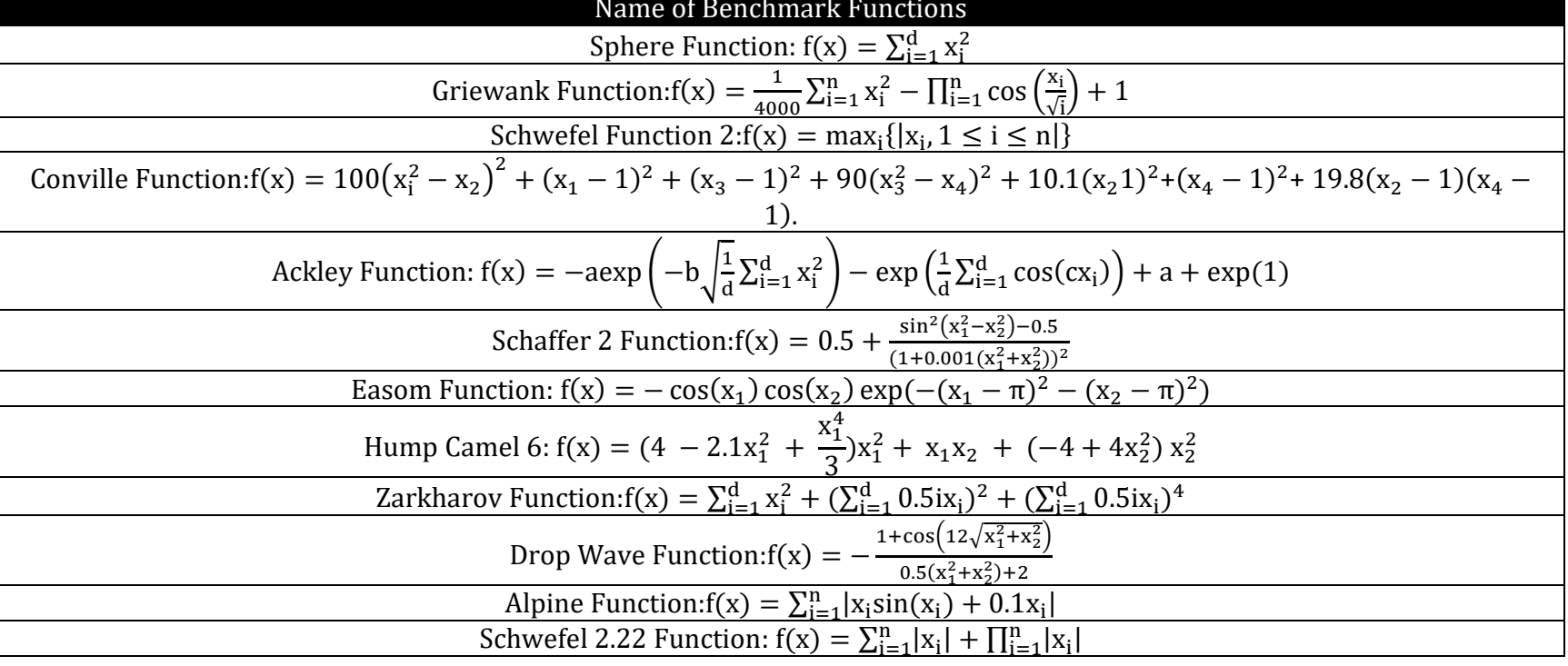




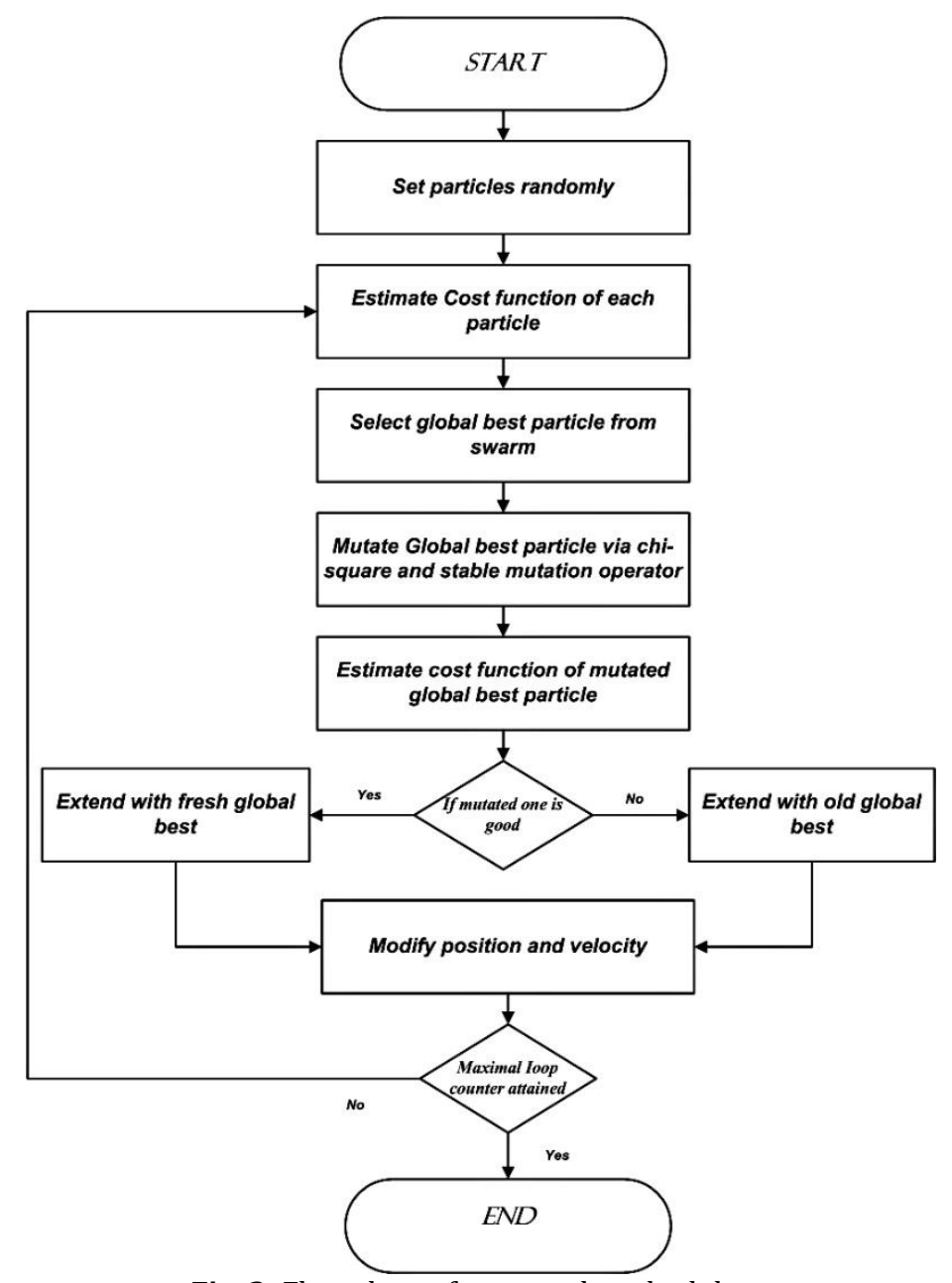

Fig. 2: Flow chart of proposed methodology

\section{References}

Andrews PS (2006). An investigation into mutation operators for particle swarm optimization. In the IEEE International Conference on Evolutionary Computation (CEC '06): 1044-1051. https://doi.org/10.1109/CEC.2006.1688424

Beni G and Wang J (1989). Swarm Intelligence in Cellular Robotic Systems. In the NATO Advanced Workshop on Robots and Biological Systems, Tuscany, Italy. https://doi.org/10.1007/978-3642-58069-7_38

Esquivel SC and Coello CC (2003). On the use of particle swarm optimization with multimodal functions. In the IEEE Congress on Evolutionary Computation (CEC '03): 1130-1136. https://doi.org/ 10.1109/CEC.2003.1299795

Hashim R, Imran M and Khalid NEA (2013). Particle swarm optimization (PSO) variants with Triangular Mutation. Journal of Engineering and Technology (JET), 4(1): 95-107.

Higashi N and Iba H (2003). Particle swarm optimization with Gaussian mutation. In the Proceedings of the 2003 IEEE Swarm Intelligence Symposium (SIS '03): 72-79. https://doi.org/ $10.1109 /$ SIS.2003.1202250
Imran M, Hashim R and Khalid NEA (2012). Opposition based particle swarm optimization with student $T$ mutation (OSTPSO). In the $4^{\text {th }}$ IEEE Conference on Data Mining and Optimization $\quad$ (DMO): $80-85$. https://doi.org/10.1109/DM0.2012.6329802

Imran M, Hashim R and Khalid NEA (2014). Laplace mutated particle swarm optimization (LMPSO). Life Science Journal, 11(10): 292-299.

Imran M, Manzoor Z, Ali S and Abbas Q (2011). Modified particle swarm optimization with student $\mathrm{T}$ mutation (STPSO). In the IEEE International Conference on Computer Networks and Information Technology (ICCNIT): 283-286. http://dx.doi.org/10.1109/ICCNIT.2011.602094 4

Kennedy J and Eberhart R (1995). Particle Swarm Optimization. In the IEEE International Conference on Neural Networks. 1942-1948. https://doi.org/10.1109/ICNN.1995.488968

Krohling RA and Mendel E (2009). Bare bones particle swarm optimization with Gaussian or Cauchy jumps. In the IEEE Congress on Evolutionary Computation (CEC '09): 3285-3291. https://doi.org/10.1109/CEC.2009.4983361 
Li C, Liu Y, Zhou A, Kang L and Wang H (2007). A fast particle swarm optimization algorithm with Cauchy mutation and natural selection strategy. In the 2nd international conference on Advances in computation and intelligence (ISICA'07), Wuhan, China: 334-343.

Wang H, Li C, Liu Y and Zeng S (2007). A hybrid particle swarm algorithm with Cauchy mutation. In the IEEE Swarm Intelligence Symposium (SIS '07): 356-360. https://doi.org/10.1109/SIS.2007. 367959
Wu X and Zhong M (2009). Particle swarm optimization based on power mutation. In the ISECS International Colloquium on Computing, Communication, Control, and Management (CCCM): 464-467. https://doi.org/10.1109/ CCCM.2009.5267559

Zhan ZH, Zhang J, Li Y and Chung HSH (2009). Adaptive particle swarm optimization. IEEE Transactions on Systems, Man, and Cybernetics, Part B (Cybernetics), 39(6): 1362-1381. 